\title{
Business Clusters in China: from a Distinctive Perspective
}

\author{
Zhaochen Han \\ The O\&M Project Management, Sinoma SCC Project \\ Na Bi WU PO box 67105 \\ AL-HASSA 31928, Kingdom of Saudi Arabia \\ Tel: 96-6-532-741-801Ｅ-mail: hanzhaochen1211@gmail.com
}

\begin{abstract}
There has been an increasing research interest in business clusters since regional clusters are found in every advanced economy and increasing in low-income economies. The existing literate tends to focus on studying China's cluster from a universal perspective. The distinctive perspective lacks of exploration. This perspective can be identified from five attributes of China's reality after open door policy. Such attributes determinates a domestic fragmentation of cluster distribution in China.
\end{abstract}

Keywords: Business Cluster, China, Distinctive perspective, Open door policy

\section{Introduction}

There has been an increasing research interest in business clusters since regional clusters are found in every advanced economy and increasing in low-income economies. Industrial concentration can promote sharpen the competitive edge of local industries. China, with no exception, is also dominated by industrial by business clusters-geographic concentration of interconnected enterprises in a particular industry that gain competitive advantages through co-location. In China, the output of many business clusters make up significant shares of the national total and even the world's total.

In china, business clusters have a fairly long history. Jingdezhen has p pottery and porcelain production clusters with a history of more than 1400 yeas; while Shene Town of Wujiang in Jiangsu Province has been one of the well-known skill centres in China for hundreds of years. Nevertheless, the development of industrial clusters gained momentum after the country implemented its reform its reform policies in 1978. Therefore, business clusters in China have been "marked" with some special Chinese socialist characteristics. For example, in Zhejiang province, under the pressure of excess manpower and limited farmland, a lot of local peasant in the rural areas had turned to turn their own household-based workshops. Thus, such self -augmented industrial were set up by the small and private enterprises; exported-oriented business clusters, largely dominated by FDI formatted in the early 1980s in Guangdong province due to this region formulated preferential policies to attract overseas investors to set up outward-processing plants; the high-tech industrial also emerged in this period. Zhongguangcun in Beijing greatly benefits from being situated in research environment where a large number of high-level research agents and universities are located; some business clusters such as food processing cluster in Luohe, Henan provinces featured as resource-driven clusters and; the wooden cluster in Linyi, Shandong province can be classified into market-driven cluster. Business clusters in China are unique.

In this paper, it takes a distinctive perspective to explore the reality of business clusters in China. This is determined by the dominant role of state-enterprises, intrinsic culture contributes, the significance of state development zones \& agglomeration economics, reegional protectionism and industrial location and distribution system after open-door policy.

\section{Insight business cluster in China: a distinctive perspective}

\subsection{Reappraising the role of China's state-owned enterprises for the development of business clusters}

The majority of enterprises in business clusters are owned by nonstate owned economies. Wenzhou, Zhejiang Province, the birthplace of China business cluster, for example, has a very small number of SOEs, over $97 \%$ of enterprises are privately owned. Unlike Zhejiang Province, Jiangsu and Guangdong centre on the development of township and village enterprises and foreign investment (TVEs) respectively.

All too often, big -bang advocates claim that SOEs in China are especially treated by Chinese authorities and have become a drag on the China economy. For example, SOEs are performed badly in terms of productive efficiency as well as being a drag economy in the sphere of distribution (Sachs \& Wing Thye, 1994a; Woo, Hai, Jin, \& Fan, 1994). However, some argue that the actual situation is really the opposite (Lo, 1999; Smyth, 2000). At the $15^{\text {th }}$ congress of the 
Chinese Communist Party (CCP) in September, 1997, the central government announced the State-owned enterprises reform program known zhuada fangxiao (grasp the big, enliven the small). A central platform of such program is enhancing large and medium sized enterprises (LMEs). According to 2006 China yearbook, LMEs are responsible for $75.43 \%$ of gross industrial output value. While some are non-state owned firms, most of LMEs are SOEs(Smyth, 2000). Owing to that LMEs has been misrepresented, Smyth (2000) states the logic of China's strategy has been misunderstood. A common approach on evaluation the efficacy of China recent sate sector reform is to take a straight comparison between the performance of the whole state-owned sector and private sector. SOEs continue to absorb more than three-fourths of domestic credit and their borrowing comprises about $60 \%$ of the total nonfinancial public debt. Taken together this crowds out investment by nonstate firms which have been the engines of China's growth. Symth(2000) argue such approach is troublesome because it does not take explicit account of the performance of the backbone of China's state owned sector, namely, LMEs. In the year of 1998, key state-owned accounting for $1 \%$ of total SOEs, contribute $85 \%$ of profits and taxes submitted to the state; $88 \%$ of annual industrial growth and $61 \%$ of annual sale.

While it is absolutely true that private sector has been growing fast, it often ignores there has been remarkably increasing in upstream industries where large-scale SOEs are dominant (Smyth, 2000). A rapid growth in upstream industries provided the inputs needed to fuel development in downstream industries (Nolan, 1995). Moreover, according to the statement of World Bank (1997), resources maybe be better allocated in private sector. However, one of significant reasons for state sectors losses should deserve closer observation. Losses have concentrated on four industrial sectors - coal mining, oil and gas, textiles and machinery (Smyth, 2000). According to (Lo, 1999), such industries accounted for 54\% of total in 1991, and the losses from coal mining, oil, nonferrous metals and military equipment sectors accounted for $90 \%$ of central-managed enterprises. In coal mining sector, for example, $85 \%$ of output was sold by planned prices, $15 \%$ by guidance prices which were two times higher than average planned price, but just $69 \%$ of the average market price (Albouy, 1991).

Although the majority of nonstate owned firms could not be allowed directly access to the system of planned materials, the reality that prices are pressed in upstream industries let inputs cheaper in downstream industries and therefore lead to develop in the private sector (Smyth, 2000). Such dual-track system provided nonstate enterprises with access to key raw materials, equipment and markets (Lin, Fang, \& Zhou, 1998).From this perspective, large scale SOEs have not diverted financial resources from private sector, to the extent instead have contributed to the impressive growth of the private sector.

Based on the work of cluster researchers, we can conclude that the development of business clusters should benefit from the contribution of LEMs. Nevertheless, the wealth presented below tends to support. At the very least, it provides a fresh viewpoint to the relationship between SOEs and business clusters. From the discussion above, LMEs contributes to nonstate sector economies. In fact, most successful industries clusters concentrate on nonstate sector. That is to say, SOEs also contribute to the development of China business clusters.

The majority of China's business clusters exist in Zhejiang, Guangdong, Fujian, Shandong provinces. Among them, Zhejiang and Guandong provinces are the most prominent in China's business clusters development (Wang, 2006). Meanwhile, due to the dominant of SOEs, it implies that China business cluster should mushroom in the light manufacturing industries, including textile and apparel, footwear, plastics, etc. For example, Wenzhou, is one of the most developed business cluster in China and is famous for its dominate private sector. According to the statistics of the following table, it shows, the business clusters in Wenzhou focus on the light industries.

\subsection{The role of culture in the spatial agglomeration of FDI}

In the past two decades, China has been quite successful in attracting foreign investment. According to the released data published by the United Nations, China has been the largest FDI recipient among developing nations, and followed the US to be the second largest one all over the world. Therefore, China has been advocated as a magnet for FDI and regarded as the "factory of the world". Market size, low costs of labour, liberalized FDI policy, political stability and improved infrastructure, such factors has been regarded as the attribution to success of China in attracting FDI (Kueh, 1992) . To some extent, while these factors facilitate huge inflows of FDI, less emphasized are China distinctive natural advantages, namely, close cultural ties with emerging regional FDI sources. On the basis of data from Chinese data, much of FDI has come from neighbouring Asian nations. This particular composition of FDI source countries as 'unique' has been noticed (Wei, 1999).

The role of business and social networks in promoting international trade has increasing research interests. In the context of China, although its regulatory framework for FDI has improved gradually since the implementation of open door policy, properties rights and contract laws are still weak and only enforced sporadically present evidence that language and cultural barriers, corruption, and legal uncertainties also present additional difficulties to overseas investors, especially Western ones.

There are approximately 55 million ethnic Chinese living outside mainland China (Yeung \& Olds, 2000). Among those, 
a large portion of overseas Chinese resides in East and Southeast Asia. In three of the newly industrialized economies, the ethnic Chinese accounts for 99\% Taiwan population, 98\% Hong Kong and 76\% Singapore. Ethnic Chinese usually are taken accounted for distinct social business network which plays an important role in the development of a region ( Yeung \& Olds, 2000). Such network also extends to other countries such as Thailand, Malaysia, Indonesia and the Philippines.

\subsection{Greater China, the significance of State development zones and agglomeration economies}

Although, the precise meaning of 'greater China' is not entirely clear, Business week, in an article in 10 October, 1988s entitled "Asian's new fire-breather," refers to greater China as the prospective result of " three way economic integration" of mainland of China, Taiwan and Hong Kong, and a more comfortable and apolitical path to reunification than any kind political settlement. On12 June, 1990, the Los Angeles Times suggests greater chains as a "superpower on a drawing board", the result of the economic integration and potential political reunification of mainland China, Taiwan, Hong Kong and Macao.

In the past decades, Hongkong and Taiwan entrepreneurial activity has been heavily concentrated in Guandong and Fujian provinces (Ash \& Kueh, 1993). In recent years, the continued economic expansion of Hong Kong and Taiwan has been constrained by shortages of land and labour as well as associated pressures on rents and payments (Ash \& Kueh, 1993). Therefore, it is important to access to low cost labour and cheap land for Hong Kong and Taiwan entrepreneurs who have re-localized their plants in Southern China.

Lo (2003) suggest that Special Economic Zones and Open Coastal Cities have their competitive edges in attracting FDI although preferential treatment spread throughout China from the south to the north and from the coastal areas to the interior. That is to say, FDI are more likely to agglomerate in such regions. The studies from some researchers have partly explained the reasons. Due to preferential FDI and the establishment of the four Special Economic Zones (SEZs) with three lie in proximate Guandong Province, foreign investment from Hong Kong manufacturing sector, for example, originally commenced in Guangdong with a form sub-contracting and consequently other forms of cross-border including factory relocation aiming at an reduce of manufacturing production costs and keeping its competitive advantages in the international market (Tuan \& $\mathrm{Ng}$, 1994). In the year of 1995, with the gravity analysis performed at the macro-level with 19 districts of Guangdong from 1988-1992, the idea of Hong Kong-Pearl River Delta regions core-periphery was first introduced (Tuan $\& \mathrm{Ng}, 1995$ ). A survey study that examines the outward investment activities reconfirms such a diffusion pattern of induced FDI, which illustrates spatial agglomeration in the areas of Pearl River Delta (PRD). Thai is, it implies that geographical boundary of PRD is co-exist with the economic boundary of the Hypothesized Hong Kong-Pear River Delta core-periphery system.

A diffusion pattern of outward investment in a city -suburban relation is suggested to be an economic subsequence of addressing land use pattern (Alonso, 1964). Such significant study with the case of manufacturing enterprises relocation of New York has contributed to the latter research on urban agglomeration economies and diseconomies (Krugman, 1991). In the context of China, FDI flows from Hong Kong (city core) to the sub-urban (PRD) via physical factory site relocation. However, such an evolving process of manufacturing relocation from the city core to its peripheral location between HK and PRD distinguishes from others due to across-custom boundaries. Such a spatial economics point has well represented the approach in "new economic geography" which has been concerned on the significance of agglomeration externalities to explain outward FDI activities (Krugman, 1998).

\subsection{Regional protectionism and industrial location}

There is a sizeable literature of industrial distribution focus on Europe and the United States, with special interests in the impact of regional integration and trade liberalization on spatial pattern of industries (Sjöberg \& Sjöholm, 2004). Under the market economies, three major strands of strands of theoretical reasoning guide these attempts to disentangles various industrial location and geographic concentration: neoclassical trade model, new trade model and new economic geography models ( Breschi \& Malerba, 2001). The neoclassical trade approach moves form a perfect competition framework, with homogeneous products and non-increasing returns to scale(Kim, 1995). Industrial location is driven by exogenous enduwoments such as technologies and/ or factors determine the location of economic activities. New trade approach claims that internal scale economies facilitate regional incentives to specialize even in a lack of distinction associated with technology or resource endowments, and enhance businesses concentrate their production in some locality. Concentration of economic activities attempts to achieve scale economic, particularly, orientated towards a large consumer market to minimize transportation costs (Krugman, 1991). Brulhart (1998) argues that a reduction of trade barriers makes underlying spatial advantages to play a greater role, bring a trend to promote regional specialization and concentration. The new economic geography literature emphasizes that geographic concentration is driven by the interaction of transportation costs and internal scale economies. Due to demand, a large number of buyers attract a larger number of producers, whereas cost linkages generate incentives for consumers to locate close to suppliers (Krugman, 1991; 1998). 
In the context of China, regional protectionism has a significant effect on the degree of regional specialization (Bai, Du, Tao, \& Tong, 2004). To some extent, while the benefits of specialization are well understood, a pre-condition for realizing these benefits---namely, free flow of goods and services across regions and countries-is not always satisfied due to possible protectionism at both international and sub-national levels (Bai, Du, Tao \& Tong, 2004, p. 398). There is a limited degree of regional specialization and the weak mobility of actors and goods in this nation (Kumar, 1994). Many studies have revealed the various creative actions taken by regional government to keep their production of scare raw materials to themselves or prevent the inflow of goods produced by other regions. For example, nevertheless, observation on unique perspective cannot be understood without reference to a Chinese particularity: the existence of regional protectionism (Brun \& Renard, 2002).As result of fiscal decentralization in the process of China's economic reform after 1978, it provides the regional authorities with a strong incentive to protect their tax base by shielding local businesses from interregional competitions (Bai et al., 2004). Furthermore, a absence of an effective promulgation from central government is to prohibit interregional trade barriers (Bai et al., 2004).There is an increasing trend on regional protectionism in China during the period of economic reform especially in the 1980s (Young, 2000). In the mid-1980s, regional protectionism in the form of " trade war" often happened along the boundaries of the various level of administrative regions (Lee, 1998). For example, "wool wars" break out in the wool-producing regions in Gansu, Inner Mongolia, Ningxia, Qinghai and Xinjang in 1985. Aiming at satisfying local demand by local production, the government agents controlled imports by establishing and implementing quotas (Brun \& Renard, 2002). As a result, for example, the wool price in Xinjiang in 1987 rose to 24 RMB per kilogram. With an increasing price, wool producers in this region were not allowed to deliver wool out of the autonomous region unless the tea and native products firms and the industrial and commercial bureaux, both at county level, had certified that these producers had carried out the procurement obligations in the first place, followed by an endorsement by the autonomous (provincial) administrative area's tea and native products, leather, textile firms and after paying a $20 \%$ pasture construction fee. To some extent, still in this autonomous region, the authorities restricted in the inflow of a total of 48 types of commodities to the region (Lee, 1998). Meanwhile, regional authorities also tend to have incentives to protect local state-owned enterprises under their administration, which are their foundation of power, their source of regional benefits as well as fiscal revenue (Bai et al., 2004).

Since the 1990s, many studies have investigated the driving force of the role of regional protectionism behind industry location in China ( Young, 2000).During the period 1992-1997, the impact of regional protectionism on the lovation of economic activities is significant to the provinces are less outward internationally (Battisse, 2002). Battisse (2002) argue that provincial authorities in provinces characterized by low advancements in reforms, weak liberalization and low degree of international openness have given priority to priority to upward vertical integration of production without consideration for prospects of goods produced. Such claims are coherent with the evidence of reduction in regional specialization in China (Battisse, 2002; Young, 2000). To some extent, these evidence that there is a negative relation between concentration and value-added growth of Chinese industries and of reduced regional specialization in a tendency of rapid global opening and liberalization.

\subsection{Distribution system of China's business cluster}

As for the issue of upgrading low-income countries' business clusters, the role of global value chain has been emphasized for at least two decades. In contrast to traditional approaches, which pay greater attention to the local interaction between businesses and institutions, the global value chains concerns clusters' linkages with extern world even more. Due to the tendency of economic globalization, it is commonly considered that business clusters in low-income economies are able to upgrade themselves only when they are involved in the global production and distribution network controlled by multinational firms. However, the growth path of some Chinese clusters indicates disparate theoretical model.

Pre-1978, governmental control is against which ongoing distribution reform should be considered. Before economic reform, production and distribution were governed by Soviet-style central planning, with market forces playing a minimal role (Taylor, 2003). Broadly speaking, the distribution network can be divided into three tiers: wholesalers at the first level were located in four big scale cities (Beiing, Guangzhou, Shanghai and Tianjin), Beijing, Guangzhou, hanghai and Tianjin; their counterparts in the second layer were placed in provincial capitals and other medium-sized cities, and distributors on the lowest rung operated from smaller cities and towns (Taylor, 2003). Such distribution system led to that not only no attempts were made to improve products and service quality, but also little or none competition form overseas products.

Post-1978, Chinese central government in 1986 decontrolled the distribution system and permitted producers to sell directly to retailers aiming at introducing market-driven incentives. However, despite state's monopolies and rigid hierarchical structure have been eliminated, its system still remained. Hence, it is increasing in potential competition with private distributors (Baldinger, 1998). In contrast of most of low-income industries where have difficult in constructing distribution system specific to small businesses and the limitation of the size of the domestic market (K. 
Ding, 2006), the function of distribution system for business clusters in China must be classified first.

\section{Conclusion: Political economy of domestic fragmentation -a new look of business cluster in China}

Such unique Chinese experience above leads to a special domestic fragmentation of cluster spatial distribution in China: business clusters are not uniformly distributed across China. Most of them exist in the South-eastern costal regions, mainly concentration in the Pearl River Delta, Yangzi River Delta and the Bohai-rim region. There are significant growth differences between coastal and interior provinces and across industrial sectors in China. These provincial and industrial disparities are result in not only by historical and geographical factors but also by political strategies that appear from the high degree of involvement of the governmental in business activities.

Although the economic landscape of regional integration has important roles on efficient resource allocation and regional economic development, compared to the states of the US, Chinese provinces are less integrated with each other. Provincial autonomy was regarded as an unique characteristic before economy reform. In the period of pre-reformed economy, China has long been regarded as truly a central planned economy in the same sense as the former Soviet Union. According to, there were only about 500 commodities under mandatory planning in contrast to with 20,000 in the former USSR, and provincial authorities took the primary role in formulation and interpretation of plans. However, some researchers still argue that China's duplicative domestic market referred to as cellularized along the provincial borders.

\section{References}

Albouy, Y. (1991). Coal pricing in china:issues and reform strategy. World Bank Discussion Paper No. 138. World Bank: Washington DC.

Alonso, W. (1964). Location and land use. Cambridge: Harvard University Press.

Ash, R. \& Kueh, Y. (1993) .Economic integration within Greater China: trade and investment flows between China, Hong Kong and Taiwan,The China Quarterly, 136, 711-745.

Bai, C.-E., Du, Y., Tao, Z., \& Tong, S. Y. (2004). Local protectionism and regional specialization: evidence from China's industries. Journal of International Economics, 63(2), 397-417.

Baldinger, P. (1998). Distribution of Goods in China: Regulatory Framework and Business Options. Washington: US-China Business Council.

Battisse, C. c. (2002). Dynamic externalities and local growth A panel data analysis applied to Chinese provinces. China Economic Review 13, 231-251.

Breschi, S. \& Malerba, F. (2001). The Geography of Innovation and Economic Clustering: Some Introductory Notes Industrial and Corporate Change, 10. No.4, 817-833.

Brulhart, M. (1998). Economic geography, industry location and trade: The evidence. World Economy, 21(6), 775.

Brun, J.-F. \& Renard, M.-F. (2002). International trade and regional specialization in China In M.-F. Renard (Ed.), China and its regions: economic growth and reform in Chinese provinces (pp. 87-101). Cheltenham, UK

Kim, S. (1995). Expansion of markets and the geographic distribution of economic activities: The trends in U.S. Quarterly Journal of Economics, 110(4), 881-908.

Krugman, P. (1991). Increasing Returns and Economic Geography. The Journal of Political Economy, 99, No. 3, 483-499.

Krugman, P. (1998). Space: The Final Frontier. Journal of Economic Perspectives, 12(2), 161-174.

Kueh, Y. Y. (1992). Foreign Investment and Economic Change in China. China Quarterly(131), 637-690.

Lee, P. K. (1998). Local economy protectionism in China's economic reform Development policy review 16(3), 281-303.

Lin, J. Y., Fang, C. \& Zhou, L. (2003). The China miracle : development strategy and economic reform Hong Kong Chinese University Press.

Lo , C . (2003). When Asia Meets China in the New Millennium: China's Role in Shapin Asia's Post-Crisis Transformation, Singapore: Pearson Prentice Hall.

Lo, D. (1999). Reappraising the performance of China's state-owned industrial enterprises, 1980-96. Cambridge Journal of Economics, 23(6), 693-718.

Nolan, P. (1995). China's rise, Russia's fall: politics, economics and planning in the transition from Stalinism. London Macmillan.

Sjöberg, Ö. \& Sjöholm, F. (2004). Trade Liberalization and the Geography of Production: Agglomeration, 
Concentration, and Dispersal in Indonesia's Manufacturing Industry Economic Geography, 80(287-310).

Smyth, R. (2000). Should China be Promoting Large-Scale Enterprises and Enterprise Groups? World Development, 28(4), 721-737.

Taylor, R. (2003). China's Consumer Revolution: Distribution Reform, Foreign Investment and the Impact of the WTO. Asian Business \& Management, 2, 184-207.

Tuan, C. \& Ng, L. F. y. (1994). Economic liberalization in China and structural adjustment of Hong Kong manufacuring. Seoul Journal of economics 7(2), 124-144.

Tuan, C. \& Ng, L. F. Y. (1995). Hong Kong's outward investment and regional economic integration with Guandong: process and implicaiton Journal of Asian Economics, 16(4), 509-523.

Wang, J. C. (2006). China's consumer-goods manufacturing clusters, with reference to Wenzhou footwear cluster. Innovatioon: management, policy\& practice 8(1-2), 160-117.

Wei, S. J. (1999). Can China and India double their inward Foreign Direct Investment? Working Paper, Harvard University

Yeung, H. W. C. \& Olds, K. (2000). Globalizaing Chinese business firms: where are they coming from, where are they heading? in glboaizaiton of Chinese business firms. New York: Martin's press.

Young, A. (2000). The Razor's edge: distributions and incremental reform in the people's republic of China. Quarterly Journal of Economics, 115(4), 1091-1135. 